\title{
A review of structural approach to flood management in coastal megacities of developing nations: current research and future directions
}

\author{
R.I. Ogie ${ }^{\mathrm{a}}$, C. Adam ${ }^{\mathrm{b}}$ and P. Perez ${ }^{\mathrm{a}}$ \\ ${ }^{a}$ Smart Infrastructure Facility, University of Wollongong, Wollongong, NSW, Australia; \\ ${ }^{b}$ Laboratoire d'Informatique de Grenoble, Grenoble, France
}

\begin{abstract}
Flooding is a major environmental problem around the world. The problem is expected to worsen with climate change, particularly in coastal megacities of developing nations $(\mathrm{CMDN})$, where vulnerability to extreme weather events is high and flood management capacity is weak. This systematic literature review focuses on structural approaches to flood management in CMDN as most of these cities rely heavily on them. The review covers the last two decades, being the period 1998-2018. Results reveal key areas of research, which are discussed within two broad categories of focus (1) establishment of new flood control projects and (2) management of existing flood control infrastructure. Several directions are suggested to guide future research efforts.
\end{abstract}

Keywords: coastal; megacities; developing nations; flood management; structural measures

\section{Introduction}

Flood has a devastating impact on people, assets and the urban environment (Dewan 2013). Within the period under investigation (1998-2018), there have been over 3,136 flood disasters around the world, affecting a total of 2 billion people, with 142,140 deaths and a total damage of US\$556 billion (EM-DAT 2017 - record as of 21 December 2017). Coastal megacities of developing nations (hereafter abbreviated as CMDN) tend to suffer the most because of their high vulnerability to extreme weather events and their weak capacity to maintain flood management capabilities (Klein, Nicholls, and Thomalla 2003; Li 2003). CMDN are defined as coastal cities located in developing nations, with a population of 10 million residents or more. Based on a UN (2016) report, there are currently 14 CMDN around the World: Shanghai, China (24.5 m); Mumbai, India (21.4 m); Karachi, Pakistan (17.1 m); Buenos Aires, Argentina (15.3 m); Kolkata, India (15 m); Istanbul, Turkey (14.4 m); Lagos, Nigeria (13.7 m); Manila, Philippines (13.1 m); Rio de Janeiro, Brazil (13 m); Tianjin, China (11.6 m); Shenzhen, China (10.8 m); Jakarta, Indonesia (10.5 m); Chennai, India (10.2 m); and Lima, Peru (10.1 m).

Flood management in CMDN can benefit from both structural and non-structural measures. Structural measures are based on "hard" infrastructure such as dikes, detention basins, drainage channels, floodgates/sluice gates, pumping stations, dams, and 
reservoirs that help in containing or controlling water (Li et al. 2016). Non-structural approaches involve "soft" measures, such as flood forecasting, flood insurance, flood risk analysis, land use planning and zoning, policy response, flood awareness programmes, flood emergency planning and response, and post-flood recovery (Li et al. 2016; Nkwunonwo, Whitworth, and Baily 2016; Zhou et al. 2017a). CMDN tend to rely more on structural measures, mainly because they are the only means to divert, hold back or control floods that would otherwise impact people, property and the urban environment (Li et al. 2016).

The focus of the present study is therefore on the structural approach to flood management and mitigation in CMDN. This systematic literature review aims to understand key areas of research and recommend future directions. The study only considers scientific articles published during the last two decades (1998-2018) and selected via two reputable academic databases: Web of Science and Scopus. Figure 1 explains the methodological flow of the review process. The remainder of the paper is organised as follows: in Section 2, background information is provided about the prevailing conditions in CMDN that may influence flood management outcomes. Section 3 discusses the various research activities focusing on the establishment of new flood control projects in CMDN. Research activities focusing on the management of existing flood control infrastructure are presented in Section 4. Finally, Section 5 concludes the paper, highlights key limitations and suggests directions for future research.

\section{Prevailing conditions in coastal megacities of developing nations}

Developing countries are known to have several prevailing conditions differing from those in developed nations, which may directly or indirectly influence flood management outcomes (Affeltranger 2001). The first one is high vulnerability to climate change effects and extreme weather events (Chan et al. 2012, 2013; Dasgupta et al. 2013). CMDN have been recognised as hotspots for climate risks because of their maritime location, high concentration of people and assets, long shorelines and low-lying nature, amongst other factors (Adelekan 2016; Dasgupta et al. 2013; Yin et al. 2015). In these cities, intense precipitation, storm surges, and sea-level rise associated with global climate change have been occurring more frequently, and as a result, flooding is a recurrent annual problem that affects millions of people (Arthurton 1998; Dasgupta et al. 2013; Douglas et al. 2008). Climate change also makes it even more difficult to predict precipitation patterns; hence, flood management in CMDN suffers from inadequate planning and preparation (Douglas et al. 2008). Scientific research could improve the knowledge and capacity of CMDN to predict expected changes in local weather patterns, including any potentially damaging impact associated with extreme weather events in the future, but not many studies on future climate patterns and location-specific impacts have focused on CMDN (Dasgupta et al. 2013). Worse still, most CMDN lack sufficient resources and government funding to support such research.

Shortage of fiscal resources and government support is another prevailing condition in CMDN that has a negative impact on flood management outcomes (Affeltranger 2001). Many developing countries have tight financial constraints, and the limited funds available for public projects are often spent on immediate primary needs of higher priority, such as drinking water and food supply (Affeltranger 2001). This leaves little or nothing to plan and prepare for floods. There are also concerns about mismanagement of public funds that should have been judiciously spent on flood 


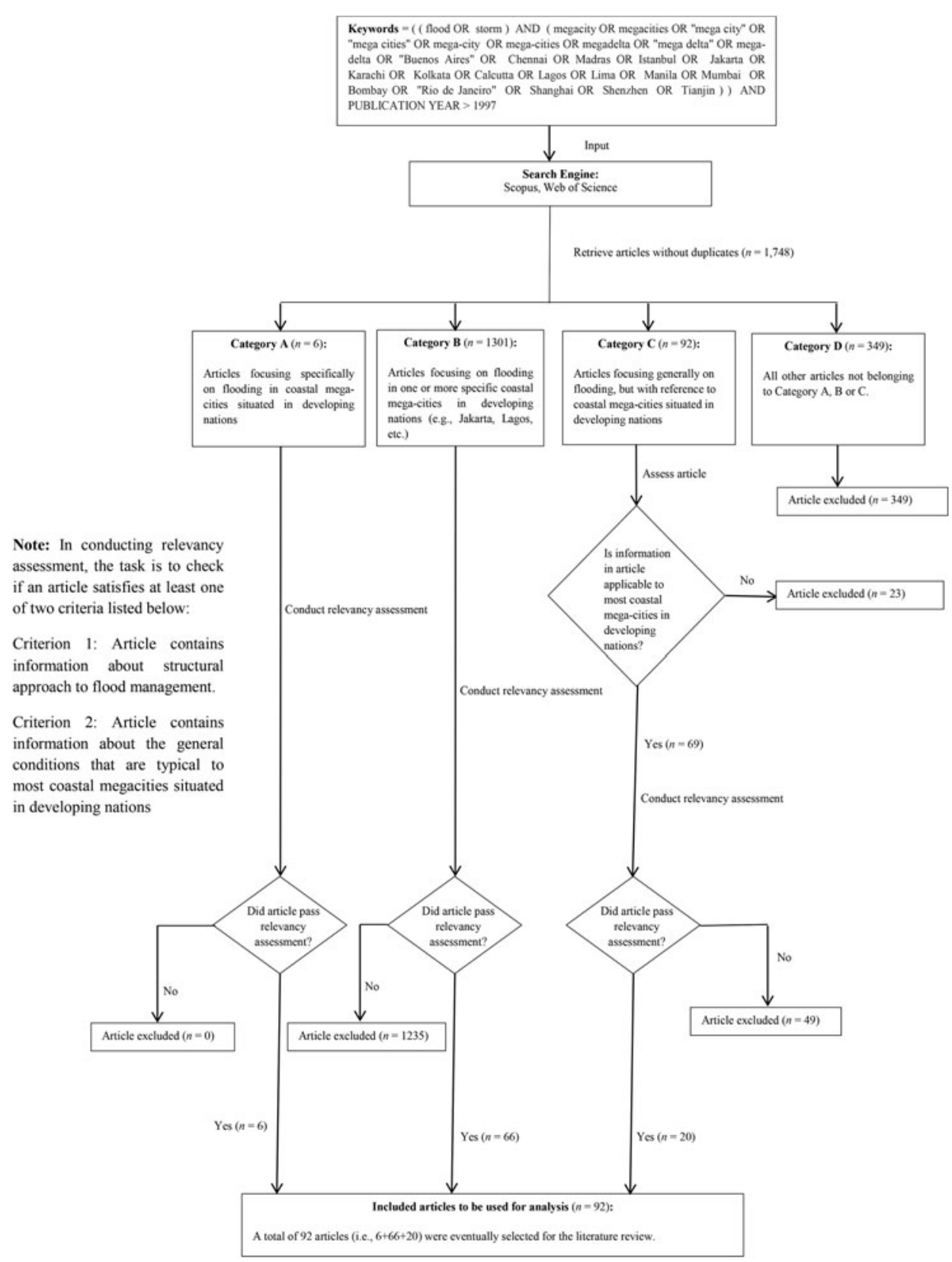

Figure 1. Literature review flow chart.

management: according to Chatterjee (2010), public funds are more likely to be used for projects that benefit only a few members of the public, particularly the formal economic sector and global clients, leaving the masses to suffer without adequate protective measures from floods. In Mumbai, for example, there are concerns that flood mitigation funds are being diverted to less effective measures, such as development of buffer zones for business districts, road work, and beautification of the environment (Chatterjee 2010). This mismanagement of flood mitigation funds results in poor 
maintenance and management of aging and deteriorating flood control infrastructure assets (Chan et al. 2012; Douglas et al. 2008), whose failure contributes to exacerbate flooding and its associated impact on a rapidly growing urban population (Li 2003).

The growing urban population in CMDN is associated with the influx of people from both rural and inland areas to the coastline (Brecht et al. 2012). For some, this migration is due to a desire to live adjacent to the sea; for others, it is proximity to job opportunities and other economic activities linked to the marine and coastal ecosystem (Li 2003). Ordinarily, large urban population signifies "increased market size, cheap labour, greater economies of scale, improved innovation, attractiveness to local and international investors, all of which stimulate the economy and help to attain the level of sustained urban growth needed to enable CMDN to respond adequately to extreme weather events such as flooding" (Ogie, Perez et al. 2017, 5). However, CMDN have not been very successful in translating the competitive advantage, not to mention the huge social capital, of large population into improved capacity for flood management. The growing population of CMDN, and the resulting high settlement density and urban congestion, complicate flood management (Dewan 2013; Li 2003). Often, the urban poor who cannot afford the cost of living in dry-land residential zones end up in flood-prone informal settlements or slums next to rivers (Li 2003).

Slums and informal settlements have implications for flood management (Adikari, Osti, and Noro 2010). In slum communities, structurally unstable shelters are built on hillsides and steep terrain along the riverbanks, making them very vulnerable to floods (Douglas et al. 2008). These slum communities are generally overcrowded, with little or no access for government authorities to conduct search and rescue during flood disasters. Due to weak connection with the general urban population, the people have the highest rates of poverty, unemployment and illiteracy (Kraas 2007; Li 2003; Mitchell 1999; Newton, Carruthers, and Icely 2012; Varis 2013), making it difficult to meaningfully engage and integrate slum dwellers into flood preparation programmes such as environmental education. Furthermore, people in slums and informal settlements are not officially recognised as part of the formal city, but rather treated as "displaced and transitory migrants who are refugees of the urban system and will go away in the near future" (Chatterjee 2010, 345). Basic facilities such as quality drinking water and sewage system are, therefore, unavailable to them (Li 2003; Sekovski, Newton, and Dennison 2012; Varis 2013), leaving them with no other option than to rely on rivers for their daily needs, including bathing, toileting, washing, and solid waste disposal (Neolaka 2013). A high volume of urban waste without adequate waste collection and disposal facilities results in coastal littering, with millions of tonnes of untreated sewage and domestic waste in water bodies (Franz and Freitas 2012; Li 2003; Sekovski, Newton, and Dennison 2012; Tibbetts 2002; Newton, Carruthers, and Icely 2012). This river pollution, by excessive waste, reduces the width and depth of waterways and potentiates fluvial flooding that occurs when the carrying capacity of a river is exceeded (Neolaka 2013). It can also lead to clogging of flood control infrastructure such as pumps and sluice gates, potentially resulting in their failure during flooding events (Ginanjar and Putra 2017).

Another prevailing condition in CMDN that affects flood management is rapid urbanisation, materialising through several construction and industrial activities, such as mining, as well as through clearing of coastal vegetation, thus removing a natural layer of flood defence (Douglas et al. 2008; Fuchs 2010; Pelling and Blackburn 2014; Sekovski, Newton, and Dennison 2012; Miguez, Veról, et al. 2012; Newton, Carruthers, and Icely 2012). Such construction activities are known to potentiate 
flooding, because impermeable surfaces such as roads, roofs, pavements, and concrete restrict infiltration of water into the ground, thereby increasing surface runoff (Douglas et al. 2008). The situation is even worse when they are not based on approved urban plans: inadequate urban growth management resulting from unplanned construction increases flood risks, particularly when structures are erected on low-lying floodplains and buildings obstruct the natural flow of water (Douglas et al. 2008; Li 2003; Newton, Carruthers, and Icely 2012).

Unplanned urbanisation gives rise to the so-called "irregular cities", where basic amenities such as quality drinking water are inadequate, and the growing population seek to exploit other natural water sources such as groundwater (Chan et al. 2012; Colven 2017; Miguez, Veról, and Bianchini 2016). Excessive groundwater extraction and associated mining activities have been identified as the major cause of land subsidence; for instance in Jakarta, land subsidence occurs at an average rate of $7.5 \mathrm{~cm}$ per year, but with certain areas in the north sinking at a rate of $17 \mathrm{~cm}$ per year, the city ranks amongst the world's fastest sinking cities (Colven 2017). Yet, Colven reported that without adequate surface water supply to meet the demands of a rapidly growing population, the people of Jakarta will continue to exploit groundwater for survival, regardless of the government's imposition of a high tax burden on this source of water. Land subsidence as a spinoff of rapid urbanisation has led to significant increase in flood risks over time ( $\mathrm{Li}$ 2003; Klein, Nicholls, and Thomalla 2003; Yin et al. 2015). Interestingly, rapid urbanisation also grows alongside industrial development.

In CMDN where the processes of urbanisation and industrial development are rapid, land reclamation is common and contributes to urban flooding. Sengupta, Chen, and Meadows (2018) extensively discuss the alarming rates of land reclamation and seaward urban expansion in CMDN. These cities (particularly Shanghai, Jakarta, Manila, Karachi, Istanbul, Chennai, Rio de Janeiro, Lagos, Lima, Buenos Aires and Mumbai) are reported to have been involved in significant land reclamation and artificial shoreline construction, in order to expand urban land and infrastructure, not only to accommodate a rapidly growing population but also to facilitate growth in commerce, trade and economic activities (Sengupta, Chen, and Meadows 2018). Many CMDN in Asia (e.g. Shenzhen) are experiencing significant economic growth because of the establishment of special economic zones (SEZs) and special tax incentives for foreign investors to operate, and are under immense pressure to expand key urban infrastructure such as transport and housing systems to sustain this growth (Chan et al. 2014). Another reason for land reclamation in CMDN is the need to "modernize". Projects such as EkoAtlantic in Lagos and the Great Garuda Sea Wall (GGSW) in Jakarta are examples of new development of world-class cities in lands reclaimed from the sea (Colven 2017). Developments on reclaimed land restrict where water can flow, expose people and urban infrastructure to flood hazards, and further complicate flood management in CMDN. Other prevailing conditions in CMDN that negatively impact flood management outcomes include the lack of well-developed insurance markets to facilitate disaster recovery, and the shortage of reliable data to support research and decision making (Brecht et al. 2012; Fuchs, Conran, and Louis 2011; Ogie, Holderness, Dunbar, et al. 2017).

\section{Research focusing on establishing new flood control infrastructure}

CMDN rely heavily on structural approach to flood management, and in the last few decades, there has been an unprecedented desire to acquire additional flood control 
infrastructure, often expensive, but deemed to be essential for coping with the demands of a changing climate, sea-level rise and the damaging impacts of large waves (Chan et al. 2014; Yin et al. 2015). Some studies have highlighted projects involving the planning and construction of additional flood control infrastructure in CMDN. For example, Adelekan (2016) identified notable flood control engineering projects that have occurred in Lagos since 1998. These include the development of the Greater Lagos Drainage Master Plan in 1998, the construction of a breakwater on the Bar Beach section of Atlantic coast in 2006, the execution of five channelisation works in 2011 , and the construction of $69 \mathrm{~km}$ concrete secondary storm water collector drainage from 2007 to 2011 . The study also provides useful information about the ongoing fivemile "Great Wall of Lagos" - a large sea revetment being developed to prevent even the worst expected storms in 1,000 years from impacting built areas in reclaimed lands such as the Victoria Island and parts of Lekki. However, there is a need for more scientifically rigorous research to further understand the future adaptation challenges associated with such a major project that entails building a new city (EkoAtlantic) in the Atlantic Ocean.

Similarly, Colven (2017) and Van der Wulp et al. (2016) discuss Jakarta's GGSW project, also known as the National Capital Integrated Coastal Development (NCICD) programme: it is a USD40 billion flood control infrastructure plan that involves constructing a giant $40 \mathrm{~km}$ long sea wall to enclose Jakarta Bay, thereby creating a vast manmade lagoon, with a new waterfront world-class city to be built around it on reclaimed land of over 1,000 hectares, in the shape of the Garuda mythical Hindu bird representing Indonesia's national symbol. A massive offshore retention lake and a set of pumping stations will be used to maintain low water levels by discharging water from Jakarta's rivers into the sea. Funding for the project is expected to come mainly from foreign aid by the Dutch government and supported by the Indonesian government, as well as private capital. In this section, we present various research activities related to the establishment of such new flood control infrastructure projects in CMDN.

\subsection{Political issues in flood control projects}

The GGSW project in Jakarta reveals a lot about the political issues associated with the construction of flood control engineering systems in CMDN. According to Colven (2017, 253), the project emerged as the preferred solution to Jakarta's flooding because of the high-powered influence of a "geographically and historically contingent technopolitical network" comprising various elements that cut across political and economic interests, flows of capital, world-class city discourses and transnational hydrological engineering expertise with ties to Dutch firms. An immediate issue with this capitalintensive project is that it does not directly address the main cause of Jakarta flooding, which is land subsidence, but is maintained as the ideal solution to Jakarta flooding due to the influence of Indonesian political elites (Colven 2017). This typifies the stronghold that political elites have on flood management initiatives within developing nations. Such powerful influence by the political elites, favouring the selfish interests of a selected few at the expense of the common good of society, undermines optimal flood management outcomes.

A study by Pante (2016) reveals that flood control in coastal areas of developing nations is a deeply political issue, with project plans often derailed due to opposition 
from political groups at different levels of governments. Many flood control projects have suffered in the past and will continue to do so as long as political meddling lingers. An evaluation of Jakarta's flood defence governance revealed that politico-institutional dysfunction greatly influenced the decades-long delay in the implementation of the Eastern Flood Canal, as opposed to popular opinion that the delay was due to budgetary constraints (Simanjuntak et al. 2012). In other words, a project that dates back to the early 1970s only became feasible and commenced actual implementation in 2003 after development in the political arena coincided with institutional reforms. These findings about the level of political disruption to project plans are crucial because they help inform risk considerations when foreign governments and funding bodies are aiming to propose research projects in developing nations.

\subsection{Environmental sustainability issue}

Another issue with the GGSW project, which is often present in most flood management projects in developing nations, is the problem of poor regard for environmental sustainability. Van der Wulp et al. (2016) highlighted environmental pollution problems as a major concern associated with implementing the GGSW project in Jakarta. Their model shows that the construction of a Giant Seawall, as proposed in the Master Plan for the NCICD programme, could lead to extremely high levels of accumulation of municipal waste and nutrients in the planned reservoirs if adequate waste water treatment is not given sufficient priority. Similarly, by using Soil and Water Assessment Tools (SWAT), Ginanjar and Putra (2017) carried out a hydrologic sediment budget modelling analysis for the Upstream Ciliwung River Basin in Jakarta, and found that the proposed construction of Sukamahi dam and Ciawi dam will result in maximum sediment concentration in the Sukamahi and Ciawi reservoirs, potentially causing environmental pollution and the clogging of dam outlets.

In Shanghai and other developing coastal megacities, where rapid urbanisation and population explosion are having an overwhelmingly negative impact on the environment, it is increasingly difficult to manage urban drainage systems in an environmentally sustainable manner (Kuan 2015). Gilbuena et al. (2013b) recommend that a thorough environmental impact assessment (EIA) should be carried out to maximise the benefits of structural flood mitigation measures in coastal urban areas. Their research, which uses Metro Manila as a case study, has shown how the rapid impact assessment matrix (RIAM) technique can be used to systematically and quantitatively evaluate both the socio-economic and environmental impacts of planned structural flood mitigation projects in highly urbanised areas. Furthermore, a recent study by Xian et al. (2018) recommend minimising the environmental impact of flood mitigation measures by harmonising future flood protection designs with the surrounding environment and ecosystem. An example is the use of large-scale, nature-based protection such as marshes or wetlands as a means of minimising the impact of storm surge flooding (Xian et al. 2018). This nature-based approach to flood mitigation provides societal and environmental benefits to the public, but its adoption in CMDN is constrained by the process of rapid urbanisation, which typically includes suppression of natural retention areas, removal of natural vegetation, and construction of large impervious areas (Miguez, Veról, et al. 2012, 2014). To compensate for the effects of rapid urbanisation on the natural water cycle of Brazilian megacities, including Rio de Janeiro, Miguez, Veról, et al. $(2012,2014)$ proposed using the so-called Compensatory 
Techniques. These are a complementary set of storage measures such as detention and retention reservoirs distributed along the riverine areas to help enhance the water storage capacity of the drainage system. However, for large-scale adoption of these techniques to take effect in CMDN, there is need for simple, yet innovative approaches of communicating the benefits to government and citizens. For example, participatory scenario-based models with direct involvement of government and citizens can be used to share the direct and indirect benefits of adopting Compensatory Techniques, including any trade-offs of competing strategies available to the coastal community.

\subsection{Sustainable urban drainage solutions}

A closely related scheme to Compensatory Techniques, that is gaining traction as an environmentally sustainable approach to urban flood management, is the concept of sustainable drainage systems (SuDS), akin to Water Sensitive Urban Design (WSUD) that has been practiced in Australia since the early 1900s. SuDS is a broad approach to flood management that requires all relevant stakeholders to work together to harmonise the process of urbanisation and urban flood control in a manner that fosters biodiversity and social benefits, including access to basic amenities such as clean water (Miguez and Veról 2016). The success of SuDS depends on the ability to tightly integrate drainage solutions with urban development in a systemic way, including through significant consideration to land use planning and low impact development (LID), to encourage minimal hydrological changes or disruption to natural flow patterns (Miguez, Rezende, and Veról 2015). SuDS are often facilitated through storage and infiltration measures wherein retention basins, infiltration trenches, green roofs, detention ponds and permeable pavements are integrated with the urban landscape (Miguez, Bahiense et al. 2012, 2014). Central to SuDS are two important pillars: (1) proper planning and (2) the need to respect watershed limits and provide adequate space for rivers (Miguez, Veról, and Bianchini 2016). Unfortunately, space is a scarce commodity in most CMDN, and they have evolved over time into "irregular" megacities, without proper city planning. According to Miguez, Bahiense et al. $(2012,2014)$, it is difficult to attain SuDS in such poorly planned megacities that are already consolidated and where space for water is constantly threatened. SuDS have been practised in Brazilian cities, including Rio de Janeiro, but their large-scale adoption in CMDN may not be viable (Miguez, Veról, and Bianchini 2016).

The viability of SuDs in CMDN is further dampened by the presence of informal settlements or slums that counteract city plans and degrade the urban environment. Miguez, Verol, and Santos (2013) proposed an alternative solution to help integrate slums and areas of irregular urban growth with the formal city, while taking into account their different terrain, resources, available infrastructure and residential needs (e.g. sewage and domestic water use). The proposed solution works by introducing a low-cost micro drainage system for the slum community, comprising small storage tanks for each home, open channels along sloppy land to aid runoff collection and central gutters to facilitate drainage to a bigger retention reservoir, which then acts as a storage measure for linking the micro drainage from the informal settlement to the formal city. By simulating different scenarios of the proposed solution for the city of Rio de Janeiro, the authors demonstrate that a suitable drainage system can be established for informal areas, and integrated seamlessly with the existing downstream formal drainage network in the city. This solution is a useful 
contribution to the enormous challenge of managing the environmental impacts of slum dwellings, particularly because it can be adapted to the unique needs of other developing coastal megacities such as Jakarta, Lagos and Manilla.

\subsection{Long-term effectiveness of flood control solutions}

Another major concern raised by scholars about high-cost flood defence construction is the fact that this type of solution has design constraints (e.g. 100-year flood), and may not be effective in the long term, considering the constantly increasing flood risks facing CMDN (Duy et al. 2018; Ke, Haasnoot, and Hoogvliet 2016; Yin et al. 2015). A study by Gilbuena et al. (2013a) revealed that structural measures could not protect Manila from the flood created by typhoon Ondoy in 2009 because these structures were designed using only 10-year and 30-year discharge return periods for the drainage works and flood protection works, respectively. A recent study by Badriana et al. (2017) demonstrates that in a prospective scenario of an "Anak-krakatau" tsunami, the proposed GGSW project in Jakarta may prove ineffective and wave collision may cause damage to the iconic Garuda bird's head. Through a series of optimisation runs, the study shows how alternative designs could help minimise the wave effects.

Furthermore, a hydrodynamic modelling study by Takagi et al. (2017), which aims to understand the long-term effectiveness of proposed dikes under continuing sea-level rise, tides and rapid land subsidence scenarios in Jakarta, shows that the effectiveness of using higher flood defence will gradually disappear over time. Xian et al. (2018) raised concern that current flood mitigation measures need to be stepped up to account for the dynamics of future climate and sea level rise in coastal cities. They noted that dynamic sea walls with flexibility for incremental height increases in line with future increases in sea level, is preferable to the traditional design of sea walls with fixed heights. However, results from Yin et al. (2015) show that hard engineering measures have limitations, and merely increasing the height of flood defences does not always address the problem, but rather transfer risks from one place to another, as water will backflow to upstream locations to cause increased water level and potential inundation in surrounding neighbourhoods. With sufficient evidence now highlighting the limitations of flood defences in CMDN, Takagi et al. (2017) recommended that from the middle of the 21 st century onwards, actions to stop land subsidence should top the list of the most effective countermeasures against coastal floods in cities such as Jakarta. This recommendation by Takagi et al. (2017) is useful because it emphasises the need for future researchers, funding bodies and the governments of CMDN to work together to explore innovative and viable solutions to the problem of land subsidence.

\subsection{Complementary and alternative solutions to expensive flood control projects}

There are concerns that in allocating resources for flood management, CMDN need to explore complementary and cheaper alternatives to big-budget hard infrastructure projects (Jena et al. 2015). In Mumbai, India, for example, authorities are exploring waterinflatable rubber dams as an alternative to traditional concrete dams; they are not only cheaper but also more flexible to serve several required functions, such as upstream water level control, irrigation, water retention, flood control and reduction of water flow velocity (Jena et al. 2015). Mohajit (2015) reported that additional investments in traditional flood control infrastructure such as drainage systems, reservoirs, dams and flood 
canals are no longer as effective in mitigating floods in coastal urban areas such as Jakarta. The study suggests the use of injection wells as a more attractive alternative in terms of the technical requirements, social impact, and financial resources involved. The author also designed mathematical models to establish a development plan for injection wells, taking into consideration the magnitudes of flooding in Jakarta, the number of injection wells required, the associated costs and implementation schedule. The paper argued that Jakarta stands to benefit from investing in injection wells, because in addition to their role as flood control infrastructure, they can also prevent seawater intrusion and ground water exploitation. While the proposed approach of using injection wells in flood management is a viable solution worth exploring in CMDN, there is need for scientifically rigorous modelling to further understand the direct and indirect impacts on the environment, taking land use and soil profiles into consideration.

Chan et al. $(2012,2013,2014)$ and Yin et al. (2015) expressed concern that coastal megacities in Asia are overly dependent on structural approaches to flooding, while little or no attention is paid to sustainable flood risk management, which transcends hard engineering measures to include non-structural complementary solutions, such as early warning systems, improved access to flood risk information, emergency evacuation planning, building codes, wider stakeholder engagement, land use, flood insurance and environmental education programs. Although these are not the focus of this study, it is important to highlight that non-structural measures are equally crucial in minimising flood impacts in CMDN.

\subsection{Determination of optimal flood control solutions}

Given the cost and resource constraints in CMDN, a number of studies have explored how to find the most effective combination of flood control solutions to attain synergised outcomes. According to Miguez et al. (2009), a supposedly effective design solution may begin to act in an ineffective way when used in combination with a different set of interventions, so that the overall outcome of the combined solution is lower than the summation of its individual effects; at the same time, it is possible to achieve synergy in flood mitigation by carefully combining the right set of solutions. Using a mathematical model that feeds from a hydrodynamic/hydrologic model, these authors show how the most optimal set of flood control interventions can be achieved by evaluating the efficacy of different combinations of possible interventions. Their analysis of the Joana River watershed in Rio de Janeiro takes into consideration both the technical and economic aspects when determining effectiveness of interventions.

The effectiveness of several flood control interventions in Jakarta, including investment in diversion channels, river improvement and capacity enhancement, have also been comparatively assessed using risk level analysis (Farid et al. 2017). This study was useful in highlighting the best solution in terms of investment value to risk level reduction. Similarly, Daksiya et al. (2017) carried out a comparative evaluation of six different flood levee construction plans for a central basin of Jakarta using a MultiCriteria Decision Analysis (MCDA) technique that takes into consideration flood extent estimates, cost of flood mitigation measures, and the social-economic impact of flooding on people. Findings from Yin et al. (2015) and Xian et al. (2018) suggest that in-depth decision making regarding priority-based selection of flood protection measures can be influenced by other factors, including flood return periods, institutional aspects of governance, topography, societal exposure, and experience with past extreme events. 
Nevertheless, the aforementioned studies remain useful in demonstrating how to optimise the selection of the most effective flood mitigation measures available to coastal cities.

\section{Research focusing on the management of existing flood control infrastructure}

In CMDN, where resources such as funds and data are very limited, it is increasingly challenging to manage flood control infrastructures in an effective and efficient manner. These infrastructures are mostly aging and deteriorating, and require improvements to their operation and maintenance. In this section, we discuss research activities related to the management of existing flood control infrastructure, focusing on improvement of operational decisions, dam-break flood routing, dam failures and associated consequences, overtopping risk assessments, and resilience measures.

\subsection{Improving operational decisions related to flood control infrastructure}

There is a significant body of research aiming to improve operational decisions related to flood control infrastructure. One set of studies focuses on achieving this through hydraulic calculations and analytical solutions that explain how water flows in compound open channels and urban drainage systems (Huai et al. 2009; Sreeja and Gupta 2007; Yang, Gao, and Huai 2010; Zeng, Wang, and Huai 2010). Another set of studies directly focuses on optimising the operations of flood control infrastructure. For example, Gu et al. (2014) proposed a means of optimising the operations of sluice gates, while Liu Cheng, and Gong (2014a) conducted a similar study for pumping stations. Nkwunonwo, Whitworth, and Baily (2016) reported that flood control in a developing nation context remains a challenging task due to other factors, such as the lack of reliable data. To address data scarcity, a recent study by Ogie, Shukla et al. (2017) recommends installing additional measuring devices such as water-level sensors, and demonstrates how to find optimal locations for the placement of a limited number of low-cost sensors. Their case study of Jakarta's flood control network aims at acquiring the most relevant data for facilitating informed decisions about the operations of different flood control infrastructure within the city.

Another closely related issue to data scarcity is knowledge deficiency. Poor knowledge of the topological connectivity of waterway networks, and of the hydraulic conditions of upstream and downstream network flows, complicates flood control decisions (Kuan 2015). For example, cities such as Jakarta and Shanghai have hundreds of man-made canals and several interconnected rivers that interact in complex ways to influence flood control outcomes; poor knowledge of these waterway networks can undermine flood control efforts. To simplify this network-type problem, Ogie, Holderness, Dunn et al. (2017) demonstrate how graph theory can be applied to construct a city-scale hydrological infrastructure network for Jakarta; this constructed network model is demonstrated to help coastal authorities better understand how their flood control infrastructures (such as pumping stations and floodgates) are both spatially and topologically connected through waterways. The network model, therefore, has potential to support real-time decision making relating to the operations of flood control infrastructure in CMDN.

\subsection{Dam-break flood routing}

Dams are important flood control infrastructure in CMDN. A significant number of studies have therefore focused on dam-break flood routing. For example, Haltas, Elçi, 
and Tayfur (2016) proposed a methodology for predicting how flood waves will propagate to densely populated areas located downstream of a failed or broken dam. Their methodology, based on the digital elevation model (DEM), land use maps, bathymetric data and flood wave routing models, was used to simulate dam breach scenarios in two different urban areas, including Istanbul, Turkey. The results show that the methodology is useful for estimating maximum flow depth, maximum flow velocity, height of flood waves, time for flood to reach residential zones, and total area affected by flood. A similar dam-break flood routing using high-precision DEM and capturing the interactions between the flood wave and the wall surfaces of buildings in a dense urban area was proposed by Wang, Chen et al. (2017). An important finding from this study is that dam-break flood in a dense urban area exhibits complex threedimensional characteristics, including turbulence, collision, reflection and vortices.

Dam break can sometimes be more complicated. For example, Zhou et al. (2017b) studied multi-source flooding involving not just a single dam-break but dam-break of cascade reservoirs. Their study used the three-dimensional $k-\varepsilon$ turbulence model and the volume-of-fluid (VOF) method in a numerical simulation of the resulting flooding. It demonstrates how the turbulent phenomena and superposition effects associated with natural river flow, upstream flooding, and downstream flooding can be accounted for in dam-break flood routing. All of the aforementioned studies on dam-break flood routing contribute significantly to coastal disaster resilience, because they aid in understanding how flood waves may propagate to cause severe impact on densely populated areas located downstream of a failed dam.

\subsection{Dam failures and associated consequences}

When a dam fails, the momentum of the flood wave can potentially cause destructive impact on the built environment, with significant consequences, including potential loss of lives in highly urbanised residential areas located downstream (Haltas, Elçi, and Tayfur 2016). With this in focus, Takagi et al. (2016) investigated the potential consequences of a dam-break tsunami-type flooding, induced mainly by land subsidence amongst other environmental factors in Jakarta, Indonesia. The study, which relies on a constructed hydrodynamic model, reveals a direct relationship between land subsidence and estimated level of inundation. The results suggest that in a dam-break tsunami-type flooding, many pedestrian pathways and roads will be cut off, with little avenue for evacuating people. The creation of a mangrove belt in front of the dike was therefore recommended as an additional safety measure.

Wang, Zhang et al. (2017) warn that dam-break floods are characterised by greater uncertainties and more complex propagation patterns and failure modes, so that conventional flood estimation techniques cannot be directly applied to predict associated losses. They propose an integrated model for life loss estimation, comprising a basic information model to address the problem of information scarcity, a flood routing simulation model to account for the propagation of flood wave, and a loss estimation model to predict loss of life. A similar life-loss risk analysis for dam break was previously conducted by Sun et al. (2010). Their loss-of-life risk evaluation model for dam break, which is based on the Graham method, takes several factors into consideration, including warning time, flood severity and overtopping probability as deduced from concurrent flood and wind. The results indicate that loss of life will vary depending on flood severity and warning time. These findings are consistent with the results of a 
previous study by Luo et al. (2009), which adopted the standard k- $\varepsilon$ model coupled with the VOF technique and the improved Graham method to evaluate loss of life in a dam failure in Shenzhen, China. The study found that warning and public comprehension degree can significantly influence life loss.

Another factor that can influence life loss in dam break floods is the ability to swiftly evacuate people from the affected areas. Hence, a study by Wang, Sun et al. (2011) aims to find an optimal evacuation scheme, based on a dam-break flood numerical simulation combining a three-dimensional dam-break mathematical model with the VOF method. The flood propagation information is fed as input to an evacuation route analysis model, which then determines blocked roads, consumption time in roads and the shortest evacuation route based on the Dijkstra algorithm for network routing. Results from a case study application in Shenzhen city show that dam-break floods have varying impact on different parts of the urban fabric, including road networks, hence the proposed model for optimising emergency evacuation from affected areas is considered useful.

It is also a useful exercise to evaluate the impacts of dam-break on the environment. Wang and Zhou (2010) proposed an EIA based on numerical simulation of dambreak flood, and applied it to evaluate the environmental risk of a reservoir dam-break in Shenzhen. The environmental risk evaluation model, which is designed based on hydraulic factors from a simulated routing process of dam-break floods, shows that if the water quality in the reservoir is good, the environmental impact of dam break to downstream areas will be minimal. However, Wang et al. (2012) later carried out a comprehensive evaluation of the consequences of a dam-break of the same dam in Shenzhen, including life loss, economic loss, social and environmental impacts. The results of their study, which uses various techniques such as the improved Graham method and the three-dimensional numerical simulation of flood propagation, show that there will be serious consequences if the dam should fail. This suggests that a more realistic estimation of dam-break consequences can only be ascertained through a comprehensive evaluation approach.

\subsection{Overtopping risk assessments}

Another significant area of research related to the management of existing flood control infrastructure in CMDN is the overtopping risk assessment of dikes, seawalls and levees. Takagi et al. (2017) recently reported that seawater is already overtopping coastal dikes and causing inundation of a vulnerable community along Jakarta's waterfront. Similarly, part of the Shanghai's sea wall built in the last century is reported to be prone to overtopping flood risk (Zhou et al. 2017a; Liu et al. 2014b). Overtopping of higher dikes is concerning because overtopped dikes prolong flooding by trapping higher volumes of water inland (Takagi et al. 2017). Based on a two-dimensional hydrodynamic numerical model built for the Yangtze River Estuary area using MIKE 21, Wang, $\mathrm{Xu}$ et al. (2011) show that the seawalls and levees are highly exposed to overtopping risk under the combined effects of land subsidence, storm tide and sealevel rise.

A similar overtopping risk analysis for a flood wall along the Huangpu River in Shanghai also shows that the flood wall is not capable of defending the city from future flood scenarios associated with both sea-level rise and rise in the Huangpu River (Zhao et al. 2016). Cruz and Santos (2015) implemented a nonlinear wave 
model to ascertain the waves and water levels that pose overtopping risks for the Roxas Boulevard Seawall in Manila, based on met-ocean forcing statistics available from the meteorological service. Results from such models can help in selecting effective flood defence measures; for example, recommending a double-wall seawall to minimise dike failures.

\subsection{Resilience of flood control structures}

With frequent failures of flood control infrastructure in CMDN, there is a growing body of research focused on the examination of the strength and resilience of flood control structures. According to Takagi et al. (2016), coastal dikes in developing countries are mostly thin and therefore susceptible to sudden collapse due to high wave impact, excessive storm surge, material ageing, sea-level rise, land subsidence, collision with vessels, and other natural hazards, such as earthquakes and landslides. For this reason, Liu et al. (2014c) reported that the safety of dike structures remains a pressing concern for coastal authorities in developing nations. This concern has also been expressed by Jiang et al. (2014), who stated that flood barriers such as seawalls can collapse unannounced if not properly monitored against progressive failure. With this level of concern about the safety of flood control infrastructure, there has been significant research to investigate the resilience of flood control infrastructure in different CMDN. These studies tend to approach the problem from slightly different dimensions, including through stability assessment (Chen, Cheng, and Yang 2006; Shi and Kong 2016; Yang et al. 2006), reliability analysis (Jiabi et al. 2013), capability assessment (Zhu et al. 2011), vulnerability assessment (Ogie et al. 2016; Ogie, Dunn et al. 2017; Ogie, Holderness, Dunn et al. 2017), deformation assessment (Pei et al. 2010) and performance assessment (Gilbuena et al. 2013a).

For example, Gilbuena et al. (2013a) conducted field inspection and observations during and after a storm in Manila to ascertain the performance of the flood control infrastructure in the city. They concluded with a recommendation to increase the safety level for flood prevention and control. Pei et al. (2010) conducted a study that focuses on real-time monitoring of deformation in seawalls. The study was conducted using the Permanent Scatterer Interferometric Synthetic AperturAR (PS-InSAR) technique, being a well-known geodetic method of constructing spatially dense datasets to estimate the rates of surface deformation over a wide area. An application of the PSInSAR technique to Shanghai seawalls revealed that serious deformation has been taking place in the seawalls around Pudong airport and Lingang town. Also, in Shanghai, Chen, Cheng, and Yang (2006) and Yang et al. (2006) investigated the long-term strength of flood-control walls. Floodwall concrete materials along the Huangpu River and near Wusongkou in Shanghai were examined to establish their seismic stability, including through testing the content of baleful components in water and soil (Yang et al. 2006).

Another study in Shanghai focused on the reliability of flood control infrastructure such as dikes, sluice gates and pumping stations (Jiabi et al. 2013). This study combines hydraulic simulation, expert judgement and knowledge of the design and condition of the flood defences to assess their performance and probability of failure when subjected to a range of loading conditions, such as river water level. Results indicate that failure could be single-node (only an individual flood control infrastructure has failed) or multi-node (more than one flood defence within the flood control system 
have failed at the same time). A previous simulation study by An et al. (2007) suggest that such single-node or multi-node failures have significant, but different, impacts on affected areas and therefore require deeper examination. Hence, there is a growing call to not only minimise damage to flood control infrastructure, but also to understand their vulnerability to damage (Shi and Kong 2016; Ogie et al. 2016). This is particularly important for $\mathrm{CMDN}$, considering that the drainage and flood control infrastructure are already below capacity for tackling current flood risks (Dasgupta et al. 2013; Kuan 2015; Zhou et al. 2017a). A number of studies, focusing on CMDN and utilising Jakarta as a study area, have recently proposed graph-theoretic methodologies for assessing and ranking the vulnerability of flood control infrastructure to damage caused by trash blockage and the high-impact force of flood water (Ogie et al. 2016; Ogie, Dunn et al. 2017; Ogie, Holderness, Dunn et al. 2017).

\section{Conclusion and future research directions}

This paper has reviewed literature published between 1998 and 2018 on the structural approach to flood management in coastal megacities of developing nations (CMDN). Research activities within this period were classified into two main groups based on their focus: (1) establishment of new flood control projects, and (2) management of existing flood control infrastructures. Key research areas discussed for new flood control projects include understanding the associated political issues, environmental sustainability, sustainable urban drainage solutions, long-term effectiveness, complementary and alternative solutions to expensive projects, and determination of optimal solutions. Key areas of research for managing existing flood control infrastructures include techniques for improving operational decisions, study of dam-break flood routing, dam failures and associated consequences, overtopping risk of flood barriers, and various assessments of stability, reliability, capability, vulnerability, deformation, and performance of infrastructures.

Based on an overview of current research, we recommend directions for future studies. First, it is important that future studies explore new solutions that take advantage of the large and growing population in CMDN. For example, there is little or no research exploring how insights from millions of citizens in a megacity context can be included as direct inputs to support decision-making related to the operations and management of flood control infrastructure. Achieving significant levels of citizen engagement or inclusiveness in flood management decisions requires trust and transparency in underlying processes. The solutions to enforce such transparency in flood management processes are currently lacking in CMDN and future studies can contribute in this direction. The emergence of such solutions, if adopted, will also help to curtail prevailing issues in $\mathrm{CMDN}$, including mismanagement of flood mitigation funds, as well as the biases and corrupt practices characterising many flood control regimes.

Another important research priority in CMDN is to develop quantitative techniques for ascertaining and minimising the impacts of slum dwellings on flood control outcomes. For example, how can we better understand and design models that allow informal settlements and slums to coexist with the formal city without further aggravating flood risks? Furthermore, there appears to be a lack of studies focusing on theory building or theoretical perspectives to flood management in CMDN. It is therefore recommended that future studies explore empirical methods such as case study and survey to not only develop new theories, but also to validate theoretical constructs that 
are fundamental to flood management practice in CMDN. These theoretical perspectives are needed to query knowledge and understand the 'why' behind new findings. Agent-based modeling will also play a key role in shaping future research on the structural approach to flood management in CMDN. Moving from traditional hydraulic and hydrologic models (e.g. LISFLOOD-FP, TR-20, MIKE FLOOD, HEC-5, HEC-RAS, ISIS and KINEROS) that are too data-intensive to be operationalised in data-scarce regions, platforms such as the GIS Agent-based Modeling Architecture (GAMA) can be used to create spatially explicit models that are simple in terms of data requirements, yet robust enough to understand various flood interventions, both structural and non-structural, within complex urban systems such as CMDN. Several studies (e.g. Adam et al. 2016; Gasmi et al. 2014) demonstrate that agent-based modeling, particularly the GAMA platform, has huge potential to contribute significantly in understanding and improving flood management initiatives.

\section{Disclosure statement}

No potential conflict of interest was reported by the authors.

\section{References}

Adam, C., F. Taillandier, E. Delay, O. Plattard, and M. Toumi. 2016. "SPRITE-Participatory Simulation for Raising Awareness About Coastal Flood Risk on the Oleron Island." In International Conference on Information Systems for Crisis Response and Management in Mediterranean Countries, edited by I. M. Dokas, N. Bellamine-Ben Saoud, J. Dugdale, and P. Díaz, 33-46. Cham: Springer.

Adelekan, I. O. 2016. "Flood Risk Management in the Coastal City of Lagos, Nigeria." Journal of Flood Risk Management 9 (3): 255-264.

Adikari, Y., R. Osti, and T. Noro. 2010. "Flood-Related Disaster Vulnerability: An Impending Crisis of Megacities in Asia." Journal of Flood Risk Management 3 (3): 185-191.

Affeltranger, B. 2001. Public Participation in the Design of Local Strategies for Flood Mitigation and Control. UNESCO IHP-V, Technical Documents in Hydrology, No. 48. Paris: UNESCO.

An, R., X. Zhang, W. Zhang, and R. Ruan. 2007. Simulation of Storm-Tide Dyke Burst Flooding Based on Zoning of Flooding and Water Logging Characteristics, 613-620. Crowmarsh Gifford: IAHS-AISH Publication.

Arthurton, R. S. 1998. "Marine-Related Physical Natural Hazards Affecting Coastal Megacities of the Asia-Pacific Region: Awareness and Mitigation." Ocean and Coastal Management 40 (1): 65-85.

Badriana, M. R., H. Bachtiar, D. Adytia, L. Sembiring, Andonowati, and E. van Groesen. 2017. "Wave Run-up of a Possible Anak-Krakatau Tsunami on Planned and Optimized Jakarta Sea Dike." In International Symposium on Earth Hazard and Disaster Mitigation, ISEDM 2016, AIP Conference Proceedings, Vol. 1857, edited by Irwan Meilano, Zulfakriza. Melville, NY: AIP Publishing. doi:10.1063/1.4987103.

Brecht, H., S. Dasgupta, B. Laplante, S. Murray, and D. Wheeler. 2012. "Sea-Level Rise and Storm Surges: High Stakes for a Small Number of Developing Countries." The Journal of Environment and Development 21 (1): 120-138.

Chan, F. K. S., O. Adekola, G. Mitchell, C. N. Ng, and A. Mcdonald. 2013. "Towards Sustainable Flood Risk Management in the Chinese Coastal Megacities. A Case Study of Practice in the Pearl River Delta." Irrigation and Drainage 62 (4): 501-509.

Chan, F. K. S., G. Mitchell, O. Adekola, and A. McDonald. 2012. "Flood Risk in Asia's Urban Mega-Deltas: Drivers, Impacts and Response." Environment and Urbanization Asia 3 (1): $41-61$.

Chan, F. K. S., N. Wright, X. Cheng, and J. Griffiths. 2014. "After Sandy: Rethinking Flood Risk Management in Asian Coastal Megacities." Natural Hazards Review 15 (2): 101-103. 
Chatterjee, M. 2010. "Slum Dwellers' Response to Flooding Events in the Megacities of India." Mitigation and Adaptation Strategies for Global Change 15 (4): 337-353.

Chen, B., H. F. Cheng, and L. D. Yang. 2006. "Prediction for Structural Settlement of FloodControl Wall Along the Bund in Shanghai." Rock and Soil Mechanics 8: 11-17.

Colven, E. 2017. "Understanding the Allure of Big Infrastructure: Jakarta's Great Garuda Sea Wall Project." Water Alternatives 10 (2): 250-264.

Cruz, E. C., and J. C. E. L. Santos. 2015. "Computational Analysis of Wall Overtopping Due to Historical Typhoons: Towards a Disaster-Aware Rehabilitation of Roxas Boulevard Seawall." In Proceedings of the World Environmental and Water Resources Congress, edited by Karen Karvazy and Veronica L. Webster, 1238-1247. Austin, TX: American Society of Civil Engineers.

Daksiya, V., H. T. Su, Y. H. Chang, and E. Y. Lo. 2017. "Incorporating Socio-Economic Effects and Uncertain Rainfall in Flood Mitigation Decision Using MCDA." Natural Hazards 87 (1): 515-531.

Dasgupta, S., A. K. Gosain, S. Rao, S. Roy, and M. Sarraf. 2013. "A Megacity in a Changing Climate: The Case of Kolkata." Climatic Change 116 (3-4): 747-766.

Dewan, A. 2013. Floods in a Megacity: Geospatial Techniques in Assessing Hazards, Risk and Vulnerability. Dordrecht: Springer.

Douglas, I., K. Alam, M. Maghenda, Y. Mcdonnell, L. McLean, and J. Campbell. 2008. "Unjust Waters: Climate Change, Flooding and the Urban Poor in Africa." Environment and Urbanization 20 (1): 187-205.

Duy, P. N., L. Chapman, M. Tight, L. V. Thuong, and P. N. Linh. 2018. "Urban Resilience to Floods in Coastal Cities: Challenges and Opportunities for Ho Chi Minh City and Other Emerging Cities in Southeast Asia." Journal of Urban Planning and Development 144 (1): 05017018 .

EM-DAT. 2017. "The Emergency Events Database-Université Catholique de Louvain (UCL)CRED, D. Guha-Sapir.” Brussels, Belgium. www.emdat.be

Farid, M., H. H. Pusparani, M. S. B. Kusuma, and S. Natasaputra. 2017. "Study on Effectiveness of Flood Control Based on Risk Level: Case Study of Kampung Melayu Village and Bukit Duri Village." Matec Web of Conferences 101: 05003. doi:10.1051/ matecconf/201710105003.

Franz, B., and M. A. V. Freitas. 2012. "Generation and Impacts of Floating Litter on Urban Canals and Rivers." Sustainability Today 167: 321-332.

Fuchs, R., M. Conran, and E. Louis. 2011. "Climate Change and Asia's Coastal Urban Cities Can They Meet the Challenge?" Environment and Urbanization Asia 2 (1): 13-28.

Fuchs, R. J. 2010. "Cities at Risk: Asia's Coastal Cities in an Age of Climate Change." Asia Pacific Issues 96: 1-2.

Gasmi, N., A. Grignard, A. Drogoul, B. Gaudou, P. Taillandier, O. Tessier, and V. D. An. 2014. "Reproducing and Exploring Past Events Using Agent-Based Geo-Historical Models." In International Workshop on Multi-Agent Systems and Agent-Based Simulation, edited by Francisco and Grimaldo, Emma Norling, 151-163. Cham: Springer.

Gilbuena, R., A. Kawamura, R. Medina, H. Amaguchi, and N. Nakagawa. 2013a. "Gap Analysis of the Flood Management System in Metro Manila, Philippines: A Case Study of the Aftermath of Typhoon Ondoy." Floods: From Risk to Opportunity 357: 32-40.

Gilbuena, R., A. Kawamura, R. Medina, H. Amaguchi, N. Nakagawa, and D. Du Bui. 2013b. "Environmental Impact Assessment of Structural Flood Mitigation Measures by a Rapid Impact Assessment Matrix (RIAM) Technique: A Case Study in Metro Manila, Philippines." Science of the Total Environment 456-457: 137-147.

Ginanjar, M. R., and S. S. Putra. 2017. "Sediment Trapping Analysis of Flood Control Reservoirs in Upstream Ciliwung River Using SWAT Model." IOP Conference Series: Earth and Environmental Science 71 (1): 012014.

$\mathrm{Gu}, \mathrm{Z}$., X. Cao, G. Liu, and W. Lu. 2014. "Optimizing Operation Rules of Sluices in River Networks Based on Knowledge-Driven and Data-Driven Mechanism." Water Resources Management 28 (11): 3455-3469.

Haltas, I., S. Elçi, and G. Tayfur. 2016. "Numerical Simulation of Flood Wave Propagation in Two-Dimensions in Densely Populated Urban Areas Due to Dam Break." Water Resources Management 30 (15): 5699-5721. 
Huai, W. X., M. Gao, Y. H. Zeng, and D. Li. 2009. "Two-Dimensional Analytical Solution for Compound Channel Flows with Vegetated Floodplains." Applied Mathematics and Mechanics 30 (9): 1121-1130.

Jena, S. K., A. Kumar, P. S. Brahmanand, A. Mishra, N. Sahoo, and D. U. Patil. 2015. "Design and Development of Rubber Dams for Watersheds in the Climate Change Scenario." In Climate Change Modelling, Planning and Policy for Agriculture, edited by A. K. Singh, J. C. Dagar, A. R. G. Arunachalam, and K. N. Shelat, 93-98. Cham: Springer.

Jiabi, X., P. Sayers, S. Dongya, and Z. Hanghui. 2013. "Broad-Scale Reliability Analysis of the Flood Defence Infrastructure within the Taihu Basin, China." Journal of Flood Risk Management 6 (1): 42-56.

Jiang, H., L. Wang, L. Li, and Z. Guo. 2014. "Safety Evaluation of an Ancient Masonry Seawall Structure with Modified DDA Method." Computers and Geotechnics 55: 277-289.

Ke, Q., M. Haasnoot, and M. Hoogvliet. 2016. "Exploring Adaptation Pathways in Terms of Flood Risk Management at a City Scale: A Case Study for Shanghai City." E3s Web of Conferences 7: 21002.

Klein, R. J., R. J. Nicholls, and F. Thomalla. 2003. "The Resilience of Coastal Megacities to Weather-Related Hazards." In Building Safer Cities: The Future of Disaster Risk. Disaster Risk Management Series No. 3, edited by A. Kreimer, M. Arnold, A. Carlin, 101-120. Washington, DC: World Bank.

Kraas, F. 2007. "Megacities and Global Change in East, Southeast and South Asia." Asien 103 (4): 9-22.

Kuan, T. 2015. "Sustainability Enhancement for Improvement of a Storm Water Drainage System in Shanghai." In World Environmental and Water Resources Congress, edited by Karen Karvazy, Hatch Mott McDonald, and Veronica L. Webster, 431-441. Austin, TX: American Society of Civil Engineers.

Li, C., X. Cheng, N. Li, X. Du, Q. Yu, and G. Kan. 2016. “A Framework for Flood Risk Analysis and Benefit Assessment of Flood Control Measures in Urban Areas." International Journal of Environmental Research and Public Health 13 (8): 787. doi:10.3390/ ijerph13080787.

Li, H. 2003. "Management of Coastal Mega-Cities: A New Challenge in the 21st Century." Marine Policy 27 (4): 333-337.

Liu, J., J. Cheng, and Y. Gong. 2014a. "Scheduling Optimization of Drainage Pumping Stations in Urbanization Polders." Transactions of the Chinese Society of Agricultural Engineering 30 (17): 141-148.

Liu, S., G. Zhong, Z. Zhou, and Y. Cai. 2014b. "Flood Control and Disaster Mitigation in Shanghai." In Vulnerability, Uncertainty, and Risk: Quantification, Mitigation, and Management, edited by Michael Beer, Siu-Kui Au, and Jim W. Hall, 998-1007. Liverpool, UK: American Society of Civil Engineers.

Liu, X., X. Du, Y. Lu, and L. Pan. 2014c. "An Investigation on Excessive Storm Surge Impacts on Typical Seawall in Shanghai." In The Eleventh ISOPE Pacific/Asia Offshore Mechanics Symposium. Shanghai, China: International Society of Offshore and Polar Engineers.

Luo, J. Q., L. Huang, Y. F. Sun, X. L. Wang, J. An, and T. Li. 2009. "Life Loss Evaluation of Dam Failure Based on VOF Method." In 3rd International Conference on Bioinformatics and Biomedical Engineering, ICBBE 2009, 1-4. Beijing, China: IEEE.

Mitchell, J. K. 1999. "Megacities and Natural Disasters." Geojournal 49 (2): 137-142.

Miguez, M. G., J. M. Bahiense, O. M. Rezende, and A. Veról. P., 2012. "New Urban Developments: Flood Control and LID: A Sustainable Approach for Urban Drainage Systems." WIT Transactions on Ecology and the Environment 155: 469-480.

Miguez, M. G., J. M. Bahiense, O. M. Rezende, and A. P. Veról. 2014. "Sustainable Urban Drainage Approach, Focusing on LID Techniques, Applied to the Design of New Housing Subdivisions in the Context of a Growing City." International Journal of Sustainable Development and Planning 9 (4): 538-552.

Miguez, M. G., F. C. B. Mascarenhas, L. P. Canedo de Magalhães, and C. F. V. D'Alterio. 2009. "Planning and Design of Urban Flood Control Measures: Assessing Effects Combination.” Journal of Urban Planning and Development 135 (3): 100-109.

Miguez, M. G., O. M. Rezende, and A. P. Veról. 2015. "City Growth and Urban Drainage Alternatives: Sustainability Challenge." Journal of Urban Planning and Development 141 (3): 04014026. 
Miguez, M. G., and A. P. Veról, 2016. "Sustainable Drainage Systems in Brazil.” In Sustainable Surface Water Management: A Handbook for SUDS, edited by Susanne M. Charlesworth and Colin A. Booth, 315-326. New Jersey: Wiley-Blackwell.

Miguez, M. G., A. P. Veról, and L. Bianchini. 2016. "Flood Risk Assessment and Management: A Case Study in Rio De Janeiro." Management of Natural Disasters 92: 29-41.

Miguez, M. G., A. P. Veról, F. C. B. Mascarenhas, and R. B. Santos. 2014. "Storage Measures as Compensatory Techniques for Urban Lowlands Flood Control." International Journal of Sustainable Development and Planning 9 (2): 225-236.

Miguez, M. G., A. P. Verol, and R. B. Santos. 2013. "Alternative Solutions for Sustainable Urban Drainage Systems Integrating Areas of Irregular Urban Growth with the Formal City." Applied Mechanics and Materials 409-410: 996-1003.

Miguez, M. G., A. P. Veról, F. C. B. Mascarenhas, R. B. Santos, and M. C. Martingil. 2012. "Compensatory Techniques on Urban Drainage for Flood Control With the Aid of Mathematical Modelling: A Case Study in Rio De Janeiro City." WIT Transactions on the Built Environment 122: 227-238.

Mohajit, O. 2015. "Mathematical Modelling of Injection Wells for Flooding Prevention in Jakarta." Procedia Engineering 125: 207-212.

Neolaka, A. 2013. "Stakeholder Participation in Flood Control of Ciliwung River, Jakarta, Indonesia." Water Resources Management VII 171: 275-285.

Newton, A., T. J. Carruthers, and J. Icely. 2012. "The Coastal Syndromes and Hotspots on the Coast." Estuarine, Coastal and Shelf Science 96: 39-47.

Nkwunonwo, U. C., M. Whitworth, and B. Baily. 2016. "A Review and Critical Analysis of the Efforts Towards Urban Flood Risk Management in the Lagos Region of Nigeria." Natural Hazards and Earth System Sciences 16 (2): 349-369.

Ogie, R. I., S. Dunn, T. Holderness, and E. Turpin. 2017. "Assessing the Vulnerability of Pumping Stations to Trash Blockage in Coastal Mega-Cities of Developing Nations." Sustainable Cities and Society 28: 53-66.

Ogie, R., T. Holderness, M. Dunbar, and E. Turpin. 2017. "Spatio-Topological Network Analysis of Hydrological Infrastructure as a Decision Support Tool for Flood Mitigation in Coastal Mega-Cities." Environment and Planning B: Urban Analytics and City Science 44 (4): 718-739.

Ogie, R. I., T. Holderness, S. Dunn, and E. Turpin. 2016. "Vulnerability Analysis of Hydrological Infrastructure to Flooding in Coastal Cities: A Graph Theory Approach." In Transforming the Future of Infrastructure Through Smarter Information: Proceedings of the International Conference on Smart Infrastructure and Construction (ICSIC), edited by R. J. Mair, K. Soga, Y. Jin, A. K. Parlikad and J. M. Schooling, 633-638 Cambridge, UK: ICE Publishing.

Ogie, R. I., T. Holderness, S. Dunn, and E. Turpin. 2017. "Assessing the Vulnerability of Hydrological Infrastructure to Flood Damage in Coastal Cities of Developing Nations." Computers, Environment and Urban Systems 68: 97-109.

Ogie, R. I., P. Perez, K. T. Win, and K. Michael. 2017. "Managing Hydrological Infrastructure Assets for Improved Flood Control in Coastal Mega-Cities of Developing Nations." Urban Climate https://doi.org/10.1016/j.uclim.2017.09.002

Ogie, R. I., N. Shukla, F. Sedlar, and T. Holderness. 2017. "Optimal Placement of Water-Level Sensors to Facilitate Data-Driven Management of Hydrological Infrastructure Assets in Coastal Mega-Cities of Developing Nations." Sustainable Cities and Society 35: 385-395.

Pante, M. D. 2016. "The Politics of Flood Control and the Making of Metro Manila." Philippine Studies: Historical and Ethnographic Viewpoints 64 (3-4): 555-592.

Pei, Y., Q. Wan, L. Wei, Z. Fang, and M. Liao. 2010. "Monitoring Seawall Deformation with Repeat-Track Space-Borne SAR Images." In Proceedings of the Symposium Dragon 2 Programme Mid-Term Results 2008-2010, ESA SP, Vol. 684. Noordwijk, The Netherlands: ESA Communications. http://adsabs.harvard.edu/abs/2010ESASP.684E..77P.

Pelling, M., and S. Blackburn. 2014. Megacities and the Coast: Risk, Resilience and Transformation. New York: Routledge.

Sekovski, I., A. Newton, and W. C. Dennison. 2012. "Megacities in the Coastal Zone: Using a Driver-Pressure-State-Impact-Response Framework to Address Complex Environmental Problems." Estuarine, Coastal and Shelf Science 96: 48-59. 
Sengupta, D., R. Chen, and M. E. Meadows. 2018. "Building Beyond Land: An Overview of Coastal Land Reclamation in 16 Global Megacities." Applied Geography 90: 229-238.

Shi, B., and X. Kong. 2016. "Back Analysis of the Stability of Flood-Control Walls Based on Analytical and Numerical Calculations." In Geo-China 2016, edited by Sherif El-Badawy, DingXin Cheng, and Mohamed Arab, 62-68. Shandong, China: American Society of Civil Engineers.

Simanjuntak, I., N. Frantzeskaki, B. Enserink, and W. Ravesteijn. 2012. "Evaluating Jakarta's Flood Defence Governance: The Impact of Political and Institutional Reforms." Water Policy 14 (4): 561-580.

Sreeja, P., and K. Gupta. 2007. "An Alternate Approach for Transient Flow Modeling in Urban Drainage Systems." Water Resources Management 21 (7): 1225-1244.

Sun, Y., D. Zhong, M. Li, and Y. Li. 2010. "Theory and Application of Loss of Life Risk Analysis for Dam Break." Transactions of Tianjin University 16 (5): 383-387.

Takagi, H., D. Fujii, M. Esteban, and X. Yi. 2017. "Effectiveness and Limitation of Coastal Dykes in Jakarta: The Need for Prioritizing Actions against Land Subsidence." Sustainability 9 (4): 619. doi:10.3390/su9040619.

Takagi, H., T. Mikami, D. Fujii, M. Esteban, and S. Kurobe. 2016. "Mangrove Forest against Dyke-Break-Induced Tsunami on Rapidly Subsiding Coasts." Natural Hazards and Earth System Sciences 16 (7): 1629-1638.

Tibbetts, J. 2002. "Coastal Cities: Living on the Edge." Environmental Health Perspectives 110 (11): A674

UN. 2016. "The World's Cities in 2016." Accessed November 25, 2016. http://www.un.org/en/ development/desa/population/publications/pdf/urbanization/the_worlds_cities_in_2016_data_ booklet.pdf

van der Wulp, S. A., L. Dsikowitzky, K. J. Hesse, and J. Schwarzbauer. 2016. "Master Plan Jakarta, Indonesia: The Giant Seawall and the Need for Structural Treatment of Municipal Waste Water." Marine Pollution Bulletin 110 (2): 686-693.

Varis, O. 2013. Megacities, Development and Water. Water Management for Large Cities. Oxford: Routledge.

Wang, C., S. Zhang, Y. Tan, F. Pan, and L. Yan. 2017. "Life Loss Estimation Based on DamBreak Flood Uncertainties and Lack of Information in Mountainous Regions of Western China." Transactions of Tianjin University 23 (4): 370-379.

Wang, J., S. Xu, M. Ye, and J. Huang. 2011. "The MIKE Model Application to Overtopping Risk Assessment of Seawalls and Levees in Shanghai." International Journal of Disaster Risk Science 2 (4): 32-42.

Wang, X., and Z. Zhou. 2010. "Study on Environmental Risk of Dam Failure." In 2010 4th International Conference on Bioinformatics and Biomedical Engineering (iCBBE), 1-3. Chengdu, China: IEEE.

Wang, X., W. Chen, Z. Zhou, Y. Zhu, C. Wang, and Z. Liu. 2017. "Three-Dimensional Flood Routing of a Dam Break Based on a High-Precision Digital Model of a Dense Urban Area." Natural Hazards 86 (3): 1147-1174.

Wang, X. L., Q. S. Wang, R. R. Sun, and X. F. Ao. 2012. "Study on the Gray Fuzzy Comprehensive Evaluation Model about Dam-Break Consequences." Advanced Materials Research 594: 1965-1968.

Wang, X., R. Sun, Z. Zhou, and L. Huang. 2011. "Optimal Evacuation Scheme Based on DamBreak Flood Numerical Simulation." Transactions of Tianjin University 17 (6): 424-430.

Xian, S., J. Yin, N. Lin, and M. Oppenheimer. 2018. "Influence of Risk Factors and Past Events on Flood Resilience in Coastal Megacities: Comparative Analysis of NYC and Shanghai." Science of the Total Environment 610: 1251-1261.

Yang, L., Y. U. Geng. D., and D. 2006. "Long-Term Strength Evaluation of Floodwall Structure along Huangpu River." Journal of Tongji University (Natural Science) 9: 5-11.

Yang, Z. H., W. Gao, and W. X. Huai. 2010. "Secondary Flow Coefficient of Overbank Flow." Applied Mathematics and Mechanics 31 (6): 709-718.

Yin, J., D. Yu, Z. Yin, J. Wang, and S. Xu. 2015. "Modelling the Anthropogenic Impacts on Fluvial Flood Risks in a Coastal Mega-City: A Scenario-Based Case Study in Shanghai, China." Landscape and Urban Planning 136: 144-155. 
Zeng, Y. H., Y. H. Wang, and W. Huai. X 2010. "Hydraulic Calculation of Steady Uniform Flows in Trapezoidal Compound Open Channels." Applied Mathematics and Mechanics 31 (8): 947-954.

Zhao, G., Y. Li, D. Cui, and X. Du. 2016. "Overtopping Risk Analysis of Downtown Section of Flood Wall in Shanghai along Huangpu River." Advances in Science and Technology of Water Resources 36 (3): 57-61 and 67.

Zhou, Z., S. Liu, G. Zhong, and Y. Cai. 2017a. "Flood Disaster and Flood Control Measurements in Shanghai." Natural Hazards Review 18 (1): B5016001.

Zhou, Z., X. Wang, W. Chen, S. Deng, and M. Liu. 2017b. "Numerical Simulation of DamBreak Flooding of Cascade Reservoirs." Transactions of Tianjin University 23 (6): 570-581.

Zhu, J., L. Pan, Y. Lu, and S. Xu. 2011. "Storm Surge Defense Capability Assessment of a Newly-Built Sea Dike at Harbor City, Shanghai." In The Twenty-First International Offshore and Polar Engineering Conference, 127-132. Maui, Hawaii: International Society of Offshore and Polar Engineers. 